\title{
Pelayanan Etika Klinis
}

\author{
Henky $^{\mathrm{I}}$ \\ 'Departemen Kedokteran Forensik, Universitas Udayana
}

\begin{abstract}
Kata Kunci
Etika klinis, konsultasi etika, bioetika

Korespondensi

henky@unud.ac.id

Publikasi

(C) 2018 JEKI/ilmiah.id

DOI

I0.26880/jeki.v2i2.I7

Tanggal masuk: I7 Desember 2017

Tanggal ditelaah: 6 Mei 2018

Tanggal diterima: Io Mei 2018

Tanggal publikasi: 12 Juni 2018

Abstrak Bioetika telah berkembang di Indonesia sejak tahun 2000 , namun sampai saat ini belum banyak rumah sakit di Indonesia yang menyediakan pelayanan etika klinis. Sebagai konsekuensinya, belum ada publikasi tentang etika klinis sampai saat ini di Indonesia. Sementara itu, kemajuan teknologi medis telah memicu timbulnya berbagai dilema etis yang harus diputuskan oleh para klinisi yang berpraktik di sarana pelayanan kesehatan. Idealnya, keputusan tersebut seharusnya didukung pendapat ahli etika. Oleh karena itu, makalah ini akan menelaah pentingnya pelayanan etika klinis di Indonesia dengan meninjau pengalaman pelayanan etika klinis yang terdapat di Inggris, Amerika Serikat, dan Australia. Meskipun terdapat beberapa kritik terhadap pelayanan etika klinis, temuan empiris telah menunjukkan manfaat dari pelayanan etika klinis. Tulisan ini mendukung pendapat bahwa pelayanan etika klinis harus dibentuk di seluruh sarana pelayanan kesehatan yang berada di Indonesia karena meningkatkan kualitas pelayanan kesehatan, mengurangi risiko tuntutan hukum, dan memenuhi kehendak masyarakat.
\end{abstract}

\begin{abstract}
Bioethics has been developing in Indonesia since 2000, but to this date only few hospitals in Indonesia provide clinical ethics services. Therefore, there has been no publication on clinical ethics until now in Indonesia. Meanwhile, the advance of medical technology certainly gives rise to many ethical dilemmas that must be resolved by clinicians in health facilities. These decisions, ideally, should be supported by ethicists. Hence, this paper will assess the importance of clinical ethics support in Indonesia by reviewing the experience of established clinical ethics services in the UK, the US, and Australia. Despite several critics against clinical ethics consultation, empirical findings have demonstrated the benefit of clinical ethics committees. This article will argue that clinical ethics support should be mandated in Indonesian hospitals because it can improve the quality of health care, reduce litigation risks, and is desired by community.
\end{abstract}

\section{PENDAHULUAN}

Pada abad ke-20, bioetika telah berkembang sebagai disiplin akademis dan terapan baru akibat kemajuan teknologi di bidang biomedis. Bioetika mulai berkembang ketika Van Rensselaer Potter menulis sebuah buku Bioethics: Bridge to the Future pada $1971 .{ }^{1}$ Pada tahun yang sama, The Kennedy Institute of Bioethics didirikan di Georgetown University, Washington DC. Di tempat inilah, prinsip-prinsip etika biomedis, yang populer di dunia kedokteran, diformulasikan oleh Beauchamp dan Childress. ${ }^{2}$ Prinsip-prinsip itu terdiri atas empat kaidah dasar dan empat kaidah turunan. Empat kaidah dasar yang dimaksud adalah: (1) Beneficence (melakukan perbuatan baik atau memberikan manfaat bagi orang lain) (2) Non-maleficence (tidak melakukan perbuatan merugikan atau menyakiti orang lain) (3) Respect for Autonomy (menghormati kebebasan atau keinginan orang lain), dan (4) Justice (bersikap adil pada setiap orang berdasarkan prinsip keadilan distributif dan keadilan sosial). Sedangkan empat kaidah turunan terdiri atas: 1) Veracity (jujur, memberikan informasi akurat, tepat waktu, terpercaya, dan menyeluruh) (2) Privacy (menghormati hak seseorang untuk mengontrol akses terhadap dirinya) (3) Confidentiality (menjaga kerahasiaan), dan (4) Fidelity (setia, menepati janji/kontrak, dan 
mendahulukan kepentingan pasien). Prinsipprinsip ini memiliki pengaruh besar, tidak hanya di bidang etika kedokteran secara akademis, namun juga penerapannya dalam situasi klinis untuk mengambil keputusan klinis yang etis.

Beberapa kemajuan teknologi biomedis telah memicu diskusi etika dalam praktik klinis, misalnya penemuan ventilator, teknologi bayi tabung, tes genetik, dan sebagainya. Kemajuan itu jelas menimbulkan banyak masalah etika yang harus dibahas dalam forum para ahli dengan berbagai latar belakang, antara lain komite etika klinis yang memberikan pelayanan konsultasi etika klinis. Sejak 1971, konsultasi etika klinis telah menjadi bagian dari pelayanan kesehatan di Amerika Utara, dan jumlahnya meningkat secara signifikan sekitar tahun 1980-an. ${ }^{3}$ Di Amerika Serikat, perkembangan pelayanan konsultasi etika klinis lebih cepat daripada di Eropa dan Australia. Salah satu penyebabnya adalah keputusan dari Mahkamah Agung New Jersey dalam kasus Quinlan. Keputusan tersebut merupakan keputusan pengadilan pertama yang mempertimbangkan keputusan komite etika klinis untuk mengonfirmasi prognosis Karen Ann Quinlan, seorang wanita sekarat yang berada dalam tahap terminal dari penyakit yang dideritanya. ${ }^{4-6}$

Di Indonesia, bioetika baru berkembang dalam 20 tahun terakhir, diprakarsai oleh pusat pengembangan etika Universitas Katolik Atma Jaya, Jakarta. Bioetika semakin populer di Indonesia setelah Universitas Gadjah Mada, Yogyakarta mengadakan pertemuan pertama Bioetika pada tahun 2000 sekaligus mendirikan Pusat Kajian Bioetika dan Humaniora Kedokteran. Dua tahun kemudian, dalam pertemuan kedua, mereka membentuk Jaringan Bioetika dan Humaniora Kesehatan Indonesia (JBHKI). ${ }^{7}$ Pada 2007, diadakan program non-gelar Bioetika, Hukum Kedokteran, dan Hak Asasi Manusia bagi pendidik klinis untuk mendidik mahasiswa kedokteran agar memenuhi Standar Kompetensi Dokter Indonesia 2006, khususnya di bidang Bioetika. Program ini diselenggarakan DIRJEN DIKTI bekerjasama dengan Fakultas Kedokteran Universitas Indonesia, Jakarta.
Sayangnya, kemajuan Bioetika di Indonesia tidak diikuti pengembangan etika klinis. Sampai saat ini, belum banyak rumah sakit di Indonesia yang menyediakan pelayanan etika klinis. Sehingga, sampai sekarang tidak ada artikel mengenai etika klinis di Indonesia. Oleh karena itu, makalah ini akan membahas perlunya pelayanan etika klinis di Indonesia dengan meninjau pengalaman pelayanan etika klinis yang ada di Inggris, Amerika Serikat, dan Australia.

\section{HASIL DAN PEMBAHASAN}

\section{Definisi dan Fungsi Pelayanan Etika Klinis}

Slowther, $\mathrm{dkk}^{8}$ mendefinisikan pelayanan etika klinis sebagai pemberian saran dan dukungan terhadap isu-isu etika yang timbul dari praktik klinis dan perawatan pasien pada sarana pelayanan kesehatan. Ada beberapa model pelayanan etika klinis, misalnya darurat dan tidak darurat; otoriter dan mediasi; komite etika klinis dan konsultan etika independen atau campuran. ${ }^{9-11}$ Dalam tulisan ini, istilah 'komite' dan 'konsultan' akan digunakan secara bergantian karena memiliki kesamaan makna. Pelayanan etika klinis dalam bentuk komite etika klinis memiliki 3 fungsi, yakni pendidikan dan pelatihan staf, pengembangan kebijakan rumah sakit, dan konsultasi kasus. ${ }^{8-18}$ Fungsifungsi tersebut mendukung tujuan utama pelayanan etika klinis yaitu meningkatkan kualitas pelayanan kesehatan..$^{11,19}$

\section{Kualitas Pelayanan Kesehatan dan Pengambilan Keputusan Etis}

Pelayanan etika klinis dapat meningkatkan kualitas perawatan pasien. Singer, dkk mengemukakan bahwa tujuan utama dari pelayanan etika klinis adalah meningkatkan kualitas perawatan dan kesembuhan pasien. Penting untuk dicatat bahwa pelayanan kesehatan yang berorientasi pada pasien merupakan kewajiban yang harus dipenuhi penyedia layanan kesehatan pada zaman modern. Sebagian besar masalah etika umumnya timbul langsung saat perawatan pasien, misalnya tidak menghormati dan menghargai 
martabat pasien, tidak mengomunikasikan informasi pasien dengan baik, tidak memiliki belas kasihan, dan sebagainya. ${ }^{10}$ Tidak diterapkannya "mikroetika" 20 ini tentunya akan memberikan pengalaman buruk bagi pasien sehingga menurunkan kualitas pelayanan di sarana pelayanan kesehatan tersebut. ${ }^{21}$ Kondisi itu dapat dihindari dengan memanfaatkan pelayanan etika klinis.

Dua dari tiga fungsi utama komite etika klinis adalah memfasilitasi pendidikan etika kepada dokter dan mengembangkan pedoman praktik klinis yang etis. ${ }^{11,17,18}$ Pendidikan bioetika akan memberikan pengetahuan mengenai bioetika bagi praktisi kesehatan dan pedoman etika klinis akan memandu klinisi untuk bersikap profesional saat menangani pasien. Dukungan ini diharapkan dapat mendorong para dokter untuk mempraktikkan mikroetika dalam kegiatan pelayanan kesehatan sehari-hari. Dengan demikian, terdapat hubungan kuat antara etika dan kualitas pelayanan yaitu kualitas pelayanan kesehatan dibangun berdasarkan standar dan prinsip etika, sementara itu praktik klinis yang etis meningkatkan kualitas pelayanan kesehatan. Kedua hal tersebut tidak dapat dipisahkan. ${ }^{22}$

Pelayanan etika klinis dapat meningkatkan kualitas pengambilan keputusan klinis yang etis. Hal itu sejalan dengan salah satu fungsi utama komite etika klinis, yaitu memberikan konsultasi kasus. ${ }^{11,17,18} \quad$ Siegler dan Singer ${ }^{18}$ menekankan bahwa peran utama konsultan etika adalah membantu pengambilan keputusan klinis yang baik. Konsultan etika sangat berperan dalam menghadapi keinginan pasien yang amat beragam. ${ }^{23}$ Kondisi tersebut dapat ditemukan ketika terdapat keragaman perspektif moral dalam masyarakat, yang dapat memperburuk komunikasi dokter-pasien. Hal itu umumnya ditemukan di negara-negara multikultural, salah satunya Indonesia. Pada kondisi tersebut, pasien dapat berkonsultasi kepada konsultan etika klinis demi memperoleh pandangan netral dari pihak ketiga. Dokter yang berpraktik dalam lingkungan budaya berbeda juga dapat memanfaatkan layanan konsultasi etika klinis dengan mencari konsultan etika berpengalaman dan memahami kearifan lokal.
Tentunya, konsultasi etika klinis sangat berguna untuk memfasilitasi diskusi dan membantu kedua belah pihak untuk mengidentifikasi, memahami, dan mengelola isu-isu etis menuju kesepakatan bersama. ${ }^{10}$

\section{Aspek Hukum Pelayanan Etika Klinis}

Manfaat terpenting pelayanan etika klinis ialah mencegah tuntutan hukum terhadap praktisi medis saat terjadi sengketa antara dokter dan pasien. Sebagai langkah pencegahan, komite etika klinis dapat menyiapkan panduan etika klinis yang seragam, antara lain prosedur persetujuan tindakan kedokteran, pernyataan di muka atau wasiat, pengambilan keputusan oleh wali, perintah untuk tidak melakukan resusitasi, penentuan kesia-siaan medis, pemecahan masalah terkait awal dan akhir kehidupan, dan lain-lain. Pedoman tersebut dapat memaksimalkan komunikasi dan meminimalkan konflik dokter-pasien, yang pada akhirnya dapat mengurangi potensi risiko tuntutan hukum dari pihak penerima layanan kesehatan. $^{24}$ Selain itu, hasil diskusi komite etika klinis mengenai beberapa kasus sulit dapat dianggap sebagai representasi nilai moral di masyarakat ${ }^{25}$ karena keputusan yang diambil berasal dari berbagai perspektif, yaitu dokter, filsuf, ahli etika, perawat, pasien, keluarga, sosiolog, ahli hukum, ahli antropologi, dan bahkan para ahli agama. Apabila terjadi perselisihan hukum dalam pelayanan kesehatan, seperti yang ditemukan pada kasus Quinlan, pengadilan dapat mempertimbangkan rekomendasi dari komite etika klinis sebagai prosedur formal atau keterangan ahli yang merupakan bagian dari proses peradilan. ${ }^{4,26}$

Beberapa ahli pernah keliru menduga bahwa keputusan yang dibuat komite etika klinis adalah keputusan yang bersifat paternalistik. Penyebabnya adalah karena pertemuan yang dilakukan para pakar tersebut berlangsung rahasia dan tertutup, tanpa prosedur transparan, sehingga tidak ada yang tahu bagaimana proses justifikasi atas keputusan yang dibuat. ${ }^{6,27}$ Namun, saat ini, situasinya telah berubah akibat maraknya tuntutan untuk memberikan pelayanan yang berorientasi kepada pasien dan gerakan pemenuhan hak asasi manusia 
di bidang kesehatan. Gerakan ini mendorong komite etika klinis untuk mempersiapkan prosedur yang transparan dan akuntabel saat menangani kasus etika klinis, yang siap untuk diteliti oleh setiap pihak yang berkepentingan.

Meskipun demikian, terdapat risiko potensi tuntutan hukum yang harus diantisipasi komite etika klinis. Tanggung jawab hukum mungkin dapat dilekatkan kepada komite etika klinis dan mereka dapat dianggap lalai apabila memberikan rekomendasi yang tidak tepat. ${ }^{8,14,17}$ Ketika komite etika klinis memberikan nasihat sehubungan dengan perawatan pasien, mereka juga seharusnya ikut bertanggung jawab terhadap pasien tersebut. ${ }^{8,17}$ Namun, kelalaian medis baru terbukti bila ditemukan empat hal berikut: (1) terdapat kewajiban, (2) pelanggaran terhadap pemenuhan kewajiban tersebut, (3) kerugian yang terjadi akibat konsekuensi langsung dari pelanggaran kewajiban tersebut, dan (4) tidak adanya bukti kelalaian dari pihak lawan. ${ }^{28}$

Komiteetikaklinistidak memilikikewajiban terhadap pasien, namun terhadap dokter yang meminta saran. Meskipun konsultan etika dapat dianggap sebagai bagian dari tim pelayanan kesehatan sehingga mereka memiliki kewajiban untuk merawat pasien, harus dibuktikan bahwa telah terjadi pelanggaran terhadap kewajiban tersebut. Untuk membuktikan pelanggaran kewajiban ini, perlu dilakukan tes Bolam, yang menunjukkan penyimpangan standar pelayanan. Akan tetapi, sampai saat ini, belum ada standar yang ditetapkan bagi para ahli etika.

Upaya membuktikan keterkaitan langsung antara pelanggaran kewajiban dan kerugian yang terjadi sangatlah rumit. Jika dokter telah mengikuti saran komite etika klinis dan kejadian tidak diharapkan yang telah diperkirakan sebelumnya tetap terjadi, mungkin saja terdapat hubungan kausal antara kejadian tersebut dengan instruksi komite etika klinis. ${ }^{29}$ Tetapi, kondisi ini hanya terjadi pada pelayanan etika klinis yang bersifat otoritatif. Apabila rekomendasi komite etika klinis tidak mengikat, dengan kata lain dokter memiliki pilihan untuk mengikuti atau tidak mengikuti saran komite etika klinis, tentunya dokter bertanggung jawab penuh atas kejadian yang diakibatkan pilihan mereka sendiri. Selain itu, di Amerika Serikat, di mana pelayanan konsultasi etika klinis telah ditetapkan sejak tahun 1971, tidak ada bukti bahwa konsultan etika klinis dituntut secara hukum atas konsultasi yang diberikan. ${ }^{8}$

\section{Dikehendaki atau Tidak Dikehendaki?}

Beberapa ketidaksepakatan terkait pelayanan etika klinis timbul di kalangan profesi dokter. Mereka khawatir profesionalisme tenaga kesehatan akan tergerus akibat keputusan otonom komite etika klinis. Keputusan yang sewenang-wenang dikhawatirkan dapat mengurangi kebebasan para klinisi untuk membuat keputusan moral yang tepat bagi pasien mereka. ${ }^{15-18,25}$ Hal itu dapat mengikis peran dokter dalam hubungan dokter-pasien. ${ }^{3}$ Diskusi etika klinis telah menjadi bagian tidak terpisahkan dalam praktik kedokteran sehari-hari, seperti yang diklaim editorial Lancet" (hal.897): "Debate on ethical matters is as much an integral part of everyday doctoring as choosing the best treatment for patients". Selain itu, sebagai konsekuensi dari pengurangan kebebasan dokter, para klinisi cenderung untuk melepaskan tanggung jawab keputusan moral mereka kepada komite etika klinis. Hal ini tentunya akan mengikis tanggung jawab profesional dokter. ${ }^{3,11,14}$

Konsep pelayanan etika klinis dapat berupa model mediasi. Pada jenis ini, peran konsultan etika tidak membuat keputusan, namun memfasilitasi proses pengambilan keputusan yang rasional, yang memberikan solusi terhadap permasalahan etika klinis yang sedang dihadapi. ${ }^{32,33}$ Para dokter tidak perlu mengkhawatirkan kemerosotan moral profesi dokter apabila melakukan konsultasi etika klinis. Para ahli etika memiliki kompetensi dan pengalaman yang bisa dibagi dengan kolega yang lain. ${ }^{19,34} \mathrm{Hal}$ itu merupakan salah satu bentuk kerja sama interprofesional yang harus dikembangkan untuk mencapai tujuan bersama bagi kebaikan pasien sehingga meningkatkan kepercayaan publik. ${ }^{35}$

Masalah lain yang perlu dibahas adalah respons cepat komite etika klinis dalam situasi gawat darurat. ${ }^{3,14,36}$ Dalam keadaan seperti ini, prosedur konsultasi etika klinis dapat 
menambah birokrasi baru ${ }^{3,15-17,25}$ sehingga memperlambat waktu untuk menyelamatkan jiwa pasien karena harus menunggu jawaban komite etika klinis..$^{12,14-16}$ Selain itu, komite etika klinis tidak mungkin memberikan jawaban tepat dengan cepat karena kemampuan mereka hanya memfasilitasi proses pengambilan keputusan rasional. ${ }^{5}$ Gill, dkk menyarankan agar rumah sakit di Australia menyediakan pelayanan konsultasi etika klinis darurat. Mereka telah meneliti bahwa pasien, keluarga, dan staf rumah sakit menyatakan tingkat kepuasan tinggi terhadap pelayanan konsultasi etika klinis darurat. Selain itu, komite etika klinis juga memiliki peran dalam melatih para klinisi untuk membuat keputusan etis cepat dalam situasi darurat dengan cara menganalisis kasuskasus secara retrospektif. ${ }^{17}$ Pada situasi tidak mendesak, seperti pengambilan keputusan untuk mengakhiri kehidupan, dokter masih dapat bekerja sama dengan konsultan etika klinis dalam sebuah forum tanpa memerlukan birokrasi formal.

Hal lain yang perlu dipertimbangkan adalah efektivitas biaya pelayanan etika klinis., ${ }^{3,16}$ Pimpinan sarana pelayanan kesehatan belum menyadari manfaat pelayanan etika klinis sehingga banyak personil etika klinis yang tidak dibayar. Hal ini tentunya menurunkan motivasi mereka sebagai konsultan etika klinis. ${ }^{36}$ Namun, saat ini sebagian besar sarana pelayanan kesehatan di Indonesia didanai jaminan kesehatan nasional yang pembiayaannya berasal dari pajak masyarakat. Oleh karena itu, dana tersebut harus dimanfaatkan secara optimal untuk memberi manfaat bagi masyarakat.

Pelayanan etika klinis dapat mengurangi biaya rumah sakit. Sebuah penelitian terkontrol yang dilakukan secara acak oleh Schneiderman, dkk di 7 rumah sakit Amerika Serikat melaporkan bahwa konsultasi etika bagi 278 pasien yang dirawat di ICU mengurangi lama tinggal di rumah sakit dan ICU sehingga menurunkan biaya perawatan yang tidak bermanfaat. Dowdy, $\mathrm{dkk}^{38}$ melaporkan hal yang sama, bahwa konsultasi etika klinis secara aktif akan mengurangi lama tinggal bagi 99 pasien yang sudah berada dalam keadaan terminal.
Studi analisis ekonomi Bacchetta dan Fins ${ }^{24}$ juga menunjukkan bahwa konsultasi etika klinis ternyata mengurangi biaya rumah sakit. Selain itu, seperti yang telah dibahas sebelumnya, komite etika klinis dapat memberikan panduan yang seragam sehingga dapat menghemat biaya melalui komunikasi yang lebih baik dan mengurangi konflik antara dokter dan pasien. Pada akhirnya, risiko tuntutan hukum dapat diminimalisasi, sehingga mengurangi biaya malapraktik medis.

Beberapa ahli mungkin masih menganggap bahwa pelayanan etika klinis berisiko untuk mengesampingkan kepentingan pasien ${ }^{16,17,25}$ karena pakar etika dibayar oleh rumah sakit sehingga mereka tidak dapat memediasi konflik antara dokter dan pasien secara independen dan imparsial. Para ahli etika cenderung mengambil keputusan yang menguntungkan rumah sakit karena insentif mereka tergantung dari pendapatan rumah sakit. Akan tetapi, sebagai konsultan etika klinis yang profesional, para ahli etika seharusnya berpraktik berdasarkan kode etik bagi konsultan etika klinis. ${ }^{39}$

Akhirnya, beberapa fakta empiris di Inggris mendukung kebutuhan pelayanan konsultasi etika klinis. Larcher, et $\mathrm{a}^{15}$ mendeskripsikan bahwa staf rumah sakit memerlukan sebuah forum untuk mengonsultasikan isu-isu etis, memperoleh pendidikan dan pelatihan etika, mengembangkan pedoman etika, serta merefleksikan masalah-masalah etika pada situasi klinis yang tidak darurat. Survei yang dilakukan Slowther dan Underwood ${ }^{40}$ menggambarkan bahwa 71\% tenaga kesehatan merujuk kasus-kasus dengan dilema etis ke komite etika klinis. Selanjutnya, sebuah survei nasional di Inggris dengan tingkat respons 99\% mengenai pelayanan etika klinis bagi tenaga kesehatan yang dilakukan oleh Slowther, $\mathrm{dkk}^{3}$ menunjukkan bahwa $89 \%$ responden sangat setuju bahwa mereka memerlukan pelayanan etika klinis. Tentunya, survei nasional seperti ini juga harus dilakukan di seluruh sarana pelayanan kesehatan untuk mengetahui kebutuhan pelayanan etika klinis di Indonesia. 


\section{KESIMPULAN}

Pada era pelayanan kesehatan berbasis jaminan kesehatan nasional, sarana pelayanan kesehatan di Indonesia harus memiliki pelayanan etika klinis demi meningkatkan kesejahteraan masyarakat Indonesia. Meskipun terdapat beberapa kritik terhadap pelayanan etika klinis, fakta empiris telah menunjukkan bahwa masyarakat memerlukan pelayanan etika klinis untuk meningkatkan kualitas pelayanan kesehatan dan mencegah malapraktik medis. Surveinasionaluntukmengonfirmasikebutuhan pelayanan etika klinis perlu dilakukan di Indonesia. Jika hasilnya mendukung pendapat seperti yang telah diuraikan dalam tulisan ini, tugas selanjutnya adalah menentukan model pelayanan etika klinis yang sesuai bagi masyarakat Indonesia, menyiapkan ahli bioetika berkualitas, dan merumuskan mekanisme pengendalian kualitas.

\section{KONFLIK KEPENTINGAN}

Tidak ada konflik kepentingan

\section{REFERENSI}

1. Potter VR. Bioethics, the science of survival. Bioethics: Bridge to the future. Englewood Cliffs, N.J.: Prentice-Hall; 1971. p. $1-29$.

2. Beauchamp TL, Childress JF. The principles of biomedical ethics 7th ed. New York: Oxford University Press; 2013.

3. Slowther A, Bunch C, Woolnough B, Hope T. Clinical ethics support services in the UK: an investigation of the current provision of ethics support to health professionals in the UK. Journal of Medical Ethics. 2001;27(suppl 1):i2-i8. http://dx.doi.org/10.1136/jme.27. suppl_1.i2

4. Supreme Court of New Jersey. In Re Quinlan 70 NJ 10, 355 A.2d 647; 1976. Diunduh dari: https://www.courtlistener.com/ opinion/1537678/in-re-quinlan/
5. Fleetwood JE, Arnold RM, Baron RJ. Giving answers or raising questions?: The problematic role of institutional ethics committees. Journal of Medical Ethics. 1989;15(3):137-42.

6. Wolf SM. Ethics committees and due process: Nesting rights in a community of caring. Maryland Law Review 1991;50(3):798858.

7. Hanafiah MJ, Amir A. Pengertian etika kedokteran, bioetika, dan hukum kesehatan. In: Rusmi, editor. Etika kedokteran \& hukum kesehatan. 4th ed. Jakarta: EGC; 2008. p. 1-6.

8. Slowther A, Johnston C, Goodall J, Hope T. A practical guide for clinical ethics support. University of Oxford: The Ethox Centre; 2004.

9. Moreno JD. Ethics committees and ethics consultants. Dalam: Kuhse H, Singer P (editor). A companion to bioethics. Hoboken: Wiley-Blackwell; 2010. p. 571-83.

10. Kerridge IH, Savulescu J, Komesaroff PA. Is there a future for clinical ethics services in Australia? Medical Journal of Australia. 2001;175(4):211-3.

11. Singer $\mathrm{P}$, Pellegrino E, Siegler $\mathrm{M}$. Clinical ethics revisited. BMC Medical Ethics. 2001;2(1):1. https://doi.org/10.1186/14726939-2-1

12. Slowther A. Ethics consultation and ethics committees. Dalam: Ashcroft RE, Dawson A, Draper H, McMillan J, editors. Principles of Health Care Ethics. 2nd ed. London: John Wiley \& Sons Ltd.; 2007. p. 527-34.

13. Williamson L. The quality of bioethics debate: Implications for clinical ethics committees. Journal of Medical Ethics. 2008;34(5):357-60. https://doi.org/10.1136/ jme.2007.021634

14. Gill AW, Saul P, McPhee J, Kerridge I. Acute clinical ethics consultation: The practicalities. Medical Journal of Australia. 2004;181(4):204-6. 
15. Larcher VF, Lask B, McCarthy JM. Paediatrics at the cutting edge: Do we need clinical ethics committees? Journal of Medical Ethics. 1997;23(4):245-9. https://doi. org/10.1136/jme.23.4.245

16. Larcher V. Role of clinical ethics committees. Archives of Disease in Childhood. 1999;81(2):104-6. http://dx.doi.org/10.1136/ adc.81.2.104

17. Larcher V. The development and function of Clinical Ethics Committees (CECs) in the United Kingdom Diametros. 2009;22:47-63. http://dx.doi.org/10.13153/diam.22.2009.362

18. Siegler M, Singer PA. Clinical ethics consultation: godsend or "God Squad?". The American Journal of Medicine. 1988;85(6):75960.

19. Tarzian AJ, Force ACCUT. Health care ethics consultation: An update on core competencies and emerging standards from the American Society for Bioethics and Humanities' Core Competencies Update Task Force. The American Journal of Bioethics. 2013;13(2):3-13. https://doi.org/10.1080/15265161.2012.75038 8

20. Komesaroff PA. From bioethics to microethics: The need to return ethical debate to the clinic. Dalam: Komesaroff PA, editor. Experiments in love and death: Medicine, postmodernism, microethics and the body Carlton, Vic.: Melbourne University Press; 2008. p. 20-46.

21. McClimans L, Slowther A-M, Parker M. Can UK Clinical ethics committees improve quality of care? HEC Forum. 2012;24(2):139-47. https://doi.org/10.1007/s10730-012-9175-z

22. Nelson WAP, Gardent PBCPA. Ethics and quality improvement. Healthcare Executive. 2008;23(4):40-1.

23. Nilson EG, Acres CA, Tamerin NG, Fins JJ. Clinical ethics and the quality initiative: A pilot study for the empirical evaluation of ethics case consultation. American Journal of Medical Quality. 2008;23(5):356-64. https:// doi.org/10.1177/1062860608316729
24. Bacchetta MD, Fins JJ. The economics of clinical ethics programs: A quantitative justification. Cambridge Quarterly of Healthcare Ethics. 1997;6(04):451-60.

25. Gillon R. Clinical ethics committees-pros and cons. Journal of Medical Ethics. 1997;23(4):203-4.

26. Slowther A-M, Hope T. Clinical ethics committees. BMJ. 2000;321(7262):649-50.

27. Lo B. Behind closed doors: Promises and pitfalls of ethics committees. New England Journal of Medicine. 1987;317(1):46-50. https:// doi.org/10.1056/NEJM198707023170110

28. Kerridge I, Lowe M, Stewart C. Trust, standards of care, error and negligence. Dalam: Kerridge I, Lowe M, Stewart C, editors. Ethics and Law for the Health Professions. 4th ed. Sydney: The Federation Press; 2013. p. 185-235.

29. Hendrick J. Legal aspects of clinical ethics committees. Journal of Medical Ethics. 2001;27(suppl 1):i50-i3. https://doi. org/10.1136/jme.27.suppl_1.i50

30. Siegler M. Ethics Committees: Decisions by bureaucracy. The Hastings Center Report. 1986;16(3):22-4. https://doi. org/10.2307/3563271

31. Editorial. The ethics industry. The Lancet. 1997;350(9082):897. https://doi.org/10.1016/ S0140-6736(97)21039-1

32. Fiester A. Bioethics mediation \& the end of clinical ethics as we know it. Cardozo J Conflict Resol. 2013-2014;15:501-13.

33. Agich GJ. Authority in Ethics Consultation. The Journal of Law, Medicine \& Ethics. 1995;23(3):273-83.

34. Larcher V, Slowther AM, Watson AR. Core competencies for clinical ethics committees. Clinical Medicine. 2010;10(1):30-3. https://doi.org/10.7861/clinmedicine.10-1-30 
35. Irvine R, Kerridge I, McPhee J, Freeman $\mathrm{S}$. Interprofessionalism and ethics: Consensus or clash of cultures? Journal of Interprofessional Care. 2002;16(3):199-210. https://doi. org/10.1080/13561820220146649

36. Sokol DK. The unpalatable truth about ethics committees. BMJ. 2009;339. https://doi. org/10.1136/bmj.b4179

37. Schneiderman LJ, Gilmer T, Teetzel $\mathrm{HD}$, et al. Effect of ethics consultations on nonbeneficial life-sustaining treatments in the intensive care setting: A randomized controlled trial. JAMA. 2003;290(9):1166-72. https://doi. org/10.1001/jama.290.9.1166

38. Dowdy MD, Robertson C, Bander JA. A study of proactive ethics consultation for critically and terminally ill patients with extended lengths of stay. Critical Care Medicine. 1998;26(2):252-9.

39. Code of Ethics and Professional Responsibilities for Healthcare Ethics Consultants [Internet]. 2014 [disitasi $10 \mathrm{Mei}$ 2014]. Diunduh dari: http://www.asbh.org/ uploads/files/pubs/pdfs/asbh_code_of_ethics. pdf.

40. Slowther A, Underwood M. Is there a demand for a clinical ethics advisory service in the UK? . Journal of Medical Ethics. 1998;24(3):207. 